\title{
Group Problem-Solving Training as a Low-Intensity Psychosocial Intervention for Suicidal Outpatients: An Implementation Study
}

\author{
Dóra Perczel - Forintos ${ }^{1 *}$, Dóra Antal-Uram ${ }^{1}$, Gyöngyi Ajtay ${ }^{1}$ and Flóra Enzsöl ${ }^{2}$ \\ ${ }^{1}$ Department of Clinical Psychology, Semmelweis University, Hungary \\ ${ }^{2}$ Dabas, Community Psychiatry Center, Hungary
}

*Corresponding author: Dóra Perczel-Forintos, Department of Clinical Psychology, Semmelweis University, Hungary

ARTICLE INFO
Received: 幽 February 18, 2021
Published: 豓 February 26, 2021

Citation: Dóra Perczel - Forintos, Dóra Antal-Uram, Gyöngyi Ajtay, Flóra Enzsöl. Group Problem-Solving Training as a LowIntensity Psychosocial Intervention for Suicidal Outpatients: An Implementation Study. Biomed J Sci \& Tech Res 34(2)-2021. BJSTR. MS.ID.005521.

Keywords: Suicide Prevention; Modifiable Risk Factors; Problem Solving Skills; Hopelessness; Problem Solving Training; Cultural Adaptation

Abbreviations: BDI: Beck Depression Scale; BHS: Beck Hopelessness Scale; G-PST: Group Problem-Solving Training; LIPI: Low-Intensity Psychosocial Interventions; MEPS: Mean-Ends ProblemSolving; NS: Not Significant; PLES: Paykel Life Event Scale; WAYS: Ways of Coping Questionnaire

\section{ABSTRACT}

Background: Current research on suicide prevention revealed that deficits in problem solving skills belong to the most important cognitive risk factors of suicide vulnerability. Poor problem solving skills are associated with depression, hopelessness, maladaptive coping and an increased risk of suicidality. Evidence suggests that good problem solving protects against depression or hopelessness and improvements in problem solving skills can contribute to the prevention of suicide attempts. Problem solving training (PST) as a low intensity brief cognitive-behavioural intervention can be effective in suicide prevention also.

Aims: our main aim was to accomplish the cultural adaptation of the PST in group format to improve access to evidence based low intensity psychosocial interventions for patients with attempted suicide in order to prevent further attempts. The second aim was to assess changes in problem solving skills, depression, hopelessness and negative thinking style after the intervention.

Methods: Subjects were outpatients with major depression (N=90) with attempted suicide in their psychiatric history. The procedure included a manual-based 12-week outpatient problem solving training in group format (G-PST). Measure administered before and after the intervention: Beck Depression Inventory, Beck Hopelessness Scale, Paykel Life Events Scale, Ways of Coping Questionnaire and Mean-Ends Problem Solving Test.

Results: patients showed very significant improvements in problem-solving skills, including planful problem solving, problem analysis and seeking social support. The level of depression and hopelessness as well as the negative evaluation of stressful life events were found to decrease significantly after the G-PST.

Conclusions: the findings indicate that G-PST is an effective low-intensity brief intervention which contributes significantly to the improvements of modifiable risk factors of suicide.

\section{Introduction}

Suicide is a very complex phenomenon with psychological, social, biological, cultural and environmental factors involved. Mental disorders and previous suicide attempts are the main risk factors for a completed suicide act [1,2]. Clinical studies show that untreated major depression and bipolar disorder are the most important risk factors, $90 \%$ of all suicide-related death occur among patients with current major psychiatric disorders
$[3,4]$. Several unmodifiable factors such as traumas, negative life events, gender, social insecurity and poverty may increase suicide risk. Hungary had the highest avarage sucide rate in the world between 1960 and 2000 [5]. In 1980-1985 the WHO registered 44.4 death per 100.000 inhabitants in Hungary, which is the triple of the global suicide rate of the world (14 suicides per 100.000 inhabitants. Since then there has been a huge decline in suicide 
rates and for now suicide rate is $17 / 100.000$ due to a much better recognition of depression and to more effective and comprehensive treatment approaches [1]. Effective suicide prevention strategies should focus on the modifiable risk factors such as low mood, hopelessness, dysfunctional thinking style, lack of social support and poor problem-solving abilities [1,6]. Several studies confirmed the predictive value of hopelessness in suicidal behaviour and identified it as the final step before attempting suicide [2, 6-9]. Hopelessness can be understood as the loss of perspective, an extremely negative view of the future. According to Beck's cognitive model of depression the negative view of the future is part of the negative cognitive triad, namely a negative view of the self, the world and the future [10]. The starting point of the hopelessness theory of suicide is that not the low mood or depression per se but the loss of perspective of the future, namely hopelessness can be viewed as the final stage before suicide. It has also been a wellestablished finding that hopelessness is a key factor in increasing the risk of suicidal behaviour and it has a predictive value for the repetition of suicide attempts as well as for completed suicides up to 10 years later [7].

Studies concerning the psychological processes underlying suicidal behaviour has also highlighted deficits in social problemsolving abilities. Several researchers including Walker, Chang and Hirsch [11] suggested that individuals with neurotic tendencies tended to consider problems as threats and employed impulsive, passive and/or avoidance type coping. These maladaptive ways of coping present greater risk for suicide vulnerability as mediators towards hopelessness. Several investigations highlight that emotion-oriented coping is strongly associated with poorer mental health and self-harm thoughts as well as with suicide attempts whilst problem-oriented coping is associated with better mental health [12]. Collectively, the results of these studies suggest that suicidal people are less active in their problem-solving efforts, they tend to give avoidant and impulsive responses, and also tend to have difficulty in generating alternative solutions to their problems. In a clinical study over $60 \%$ of patients with at least one suicide attempt reported that they had had at least one problem that they believed to be unsolvable and they had experienced high level of hopelessness at that time as well as strong suicidal ideation [13]. Strong research evidences have confirmed the view that meaningful association exists between suicidal ideation and poor social problem-solving skills. Pollock and Williams [14] found that suicidal patients with at least one attempt subsequently demonstrated maladaptive problem-solving skills such as increased passivity and avoidance in problem situations. A more recent study by Collinson et al. [15] also confirmed that suicidal patients presenting to hospitals with self-harm for the second or subsequent time, show poor problemsolving skills. However, some studies failed to find differences in problem-solving skills between suicidal and non-suicidal psychiatric patients. Pollock \& Williams [14] and Poós, Annus \& Perczel Forintos [16] compared patients who attempted suicide with non-suicidal psychiatric controls concluded that passive and avoidant coping were not unique to suicidal patients; however, a passive coping style in combination with the smaller number and less effective alternatives generated may increase suicide vulnerability. If this is true, major improvements in problem solving and coping skills should be an important target for interventions which aim for the effective prevention of suicidality.

\section{Problem-Solving Training}

Problem-solving training (PST) as a brief structured cognitivebehavioural and psycho-educative intervention has been adapted for several goals, context and target populations. However, it was found to be promising in decreasing the modifiable risk factors of suicide. Primary prevention of suicide should focus on the screening of groups at risk in the general population. Secondary suicide prevention aims to decrease the likelihood of a suicide attempts in high-riskindividuals such as borderline or bipolar patients, while the goal of tertiary prevention should be to diminish suicide contagion after completed suicides [17]. According to some meta-analysis the following methods proved to be effective in suicide prevention: pharmacotherapy, cognitive-behavioural therapy, reduced access to lethal means as well as responsible media reporting of suicide (e.a. [18-20]. In terms of psychosocial interventions suicidal patients often benefit from therapies that directly address intrusive suicidal thoughts, motivation and attempts. Cognitive therapy for suicide prevention, cognitive-behavioural therapy, dialectical behaviour therapy, problem-solving therapy, mentalization-based treatment and interpersonal therapy have all some positive effects for preventing suicide by decreasing both suicidal ideation and the reattempt rate of suicide attempts [21]. Systematic reviews have indicated that problem-solving therapy can be a promising cognitive-behavioural intervention following self-harm [19, 22]. For example, in an early study Salkovskis, Atha, and Storer [23] reported that PST was effective when was delivered in individual setting. Other studies did not find any evidence for the effectiveness of PST when applied in group setting [24], while in a meta-analysis Hawton et al. [18] argued that PST has the quality of evidence range between only moderate and low. Almost all studies reported that relatively short training was used consisting of 4-6 sessions. However, guidelines by the National Institute for Clinical Excellence (NICE) recommend the use of problem-solving therapy as a wellestablished intervention to prevent repeated self-harm [25].

Problem-solving training (PST) is designed to improve problemsolving skills, initially developed by D'Zurilla and Godfried in 1971 [26]. Since then, it has been extended and used in many research trials which proved its effectiveness in several mental disorders [27], especially in suicide prevention [22,23,28,29]. Meta-analysis of randomized controlled trials revealed that suicidal patients receiving PST had significantly greater improvement in their level of depression and hopelessness as well as in their problemsolving skills than suicidal patients in the control treatment 
groups [22]. In a one-year follow-up study conducted by Hatcher et al. [30] the proportion of people at high risk for further suicide attempt (based on the Beck Hopelessness Scale) was significantly lower in the group receiving problem-solving training than in the group receiving usual care. However, regarding long-term suicide prevention, current literature and the NICE guidelines strongly emphasize the importance of further research on the effectiveness of interventions carried out in clinical settings [31]. Finally, there is a large gap in the demand and the supply of the evidence based, high intensity, individually addressed psychotherapies, since the resources for providing psychotherapy in mental health care are very limited. Evidence based psychotherapies have always been hardly available due to the limited number of trained therapists in the funded healthcare. Low-intensity psychosocial interventions (LIPI) can fill this gap in clinical practice by increasing the access to psychological treatments [32]. Group interventions are widely used in clinical setting as well as in health psychology, since they allow intervening on low level / low intensity. As the group format PST is based on the principles of cognitive behaviour therapy it can enable participants to foster effective social problem-solving, overcome negative thinking and to treat underlying psychological problems. The implementation of group PST can facilitate the social support between the group members while they are able to serve as sources of feedback to each other. Furthermore, group members can facilitate brainstorming and generate alternative solutions for problem-solving together. Up to now research on the effectiveness of PST, especially of G-PST gave mixed results [33].

\section{Aims of the Study}

Suicide prevention is a serious concern world-wide and the availability of effective, evidence based psychological prevention methods is of utmost importance. PST as a short, structured lowintensity cognitive-behavioural intervention which was found to be promising in decreasing the modifiable risk factors of suicide. Although suicide rates show a steady decline in our country, effective ways of suicide prevention are much needed therefore our aim was to adopt the method of problem-solving training. In this implementation study our main goal was to use a culturally adapted problem-solving training in group format (G-PST) and investigate its effect on depression, hopelessness, problem-solving as well as coping skills as they belong to the modifiable risk factors of suicide. We hypothesized that after a 12-week G-PST participants would show improvement in problem-solving abilities, in coping skills as well as decreased level of depression and hopelessness. In addition, we investigated the number of stressful the life events and their emotional impact on the patients before and after the intervention.

\section{Methods}

\section{Participants}

A total of 90 psychiatric patients were recruited from our university outpatient clinical psychology service. Patients suitable for inclusion were those who had one or more suicide attempts within the last 5 years, fulfilled the DSM- 5 criteria of major depressive disorder and aged between 18-60 years [34]. All of them were previously treated in hospital after their suicide attempt and were on antidepressant medication. In terms of the method of suicide attempt, $73 \%$ of the patients used drug overdose, $27 \%$ cut him/herself. Patients were excluded if they had psychosis, hypomanic or manic episode or addictive disorders in their psychiatric history or they were currently at acute risk for suicide. Eligible patients were consecutively assigned to G-PST in the order of their appearance at the outpatient clinical psychology service. All of the participants provided written informed consent, as approved by the Medical Research Council, Scientific and Research Committee of the Semmelweis University (TUKEB: 233/2014). A sociodemographic and clinical data sheet was used to obtain information on the demographic and clinical history. Demographic characteristics of the participants (gender, age, marital status, education, occupation and psychiatric symptoms) can be seen in Table 1.

\section{Measures}

The following questionnaires were carried out at the baseline and after the intervention.

Beck Depression Inventory (BDI): To measure the severity of depression, the widely used BDI was administered [7,34,35]. The BDI consists of 21 questions on a four-point Likert- scale where a higher score correlates with more severe depression. Participants are asked to assess their level of their symptoms on each item. The questionnaire shows a very strong internal consistency of 0.911 .

Beck Hopelessness Scale (BHS): For measuring hopelessness we used the widely highly recognized BHS [36,37]. BHS is a selfreport inventory designed to measure three major aspects of hopelessness: feelings about the future, loss of motivation, and expectations. The test consists of 20 yes or no items; score above 9 indicates severe suicide risk. The scale showed acceptable reliability, Cronbach's alpha 0.71 .

Ways of Coping Questionnaire (WAYS): Is a 22-item selfreport measure in order to identify methods people use to cope with stressful situations [38,39]. Participants are asked to make ratings on a 4-point Likert-scale. Factors of the WAYS include problem analyses, planful problem-solving, emotion focused coping, seeking social support, escape-avoidance, emotion balancing coping. The questionnaire indicated an acceptable internal consistency as the Cronbach's alpha was 0.7 .

Mean-Ends Problem-Solving Test (MEPS): Is one of the most commonly used methods of assessing interpersonal problemsolving deficits [40,41], adapted by Poós, Annus \& Perczel Forintos [16]. The MEPS provides 10 vignettes that describe the beginning of a problem situation (e.g., conflict with the boss or partner) and its desired end-point (good relationship with boss or partner). 
Participants requested to describe how they would solve the situation for each scenario. Regarding the most common scoring method MEPS is marked for 'relevant means' that is evaluated by a trained clinical psychologist on a Likert-type scale from 0 (not effective at all) to 7 (very effective). The "relevant means" stand for the number of discrete steps that enable the protagonist to reach the solution. Two authors of this study (AGy, SzG) evaluated each MEPS in order to ensure interrater reliability. The scale showed a good internal consistency of Cronbach's alpha $=0.73$ in the present study and excellent interrater reliability $(\mathrm{r}=0.81)$

Paykel's Life Event Scale (PLES): Was created to evaluate 28 stressful life events in various domains including interpersonal, achievement, financial, legal, and adjustment events [42]. Participants are asked to check any event that they had experienced within the past year and rate its positive or negative impact on them on a 5-point Likert scale. The Cronbach's alpha 0.87 for the scale indicated excellent reliability.

\section{Procedure}

A pre-postintervention design was adapted. PST patients ( $\mathrm{N}=90)$ were recruited from the outpatient clinical psychology service of our University according to the inclusion criteria described above. Following initial assessment, they were consecutively assigned to G-PST which consisted of 8 weekly sessions followed by two booster sessions at the $10^{\text {th }}$ and $12^{\text {th }}$ week. Altogether, the G-PST consisted of 10 sessions delivered during 12 weeks. Psychological, behavioural and social characteristics of participants were assessed at baseline and after the end of treatment (at $12^{\text {th }}$ weeks). Each group consisted of 6-8 participants, the sessions were two-hour long, held weekly, facilitated by a senior cognitive-behaviour therapist and a clinical psychologist trainee as co-therapist. All the participants received a culturally adapted manualized treatment based on a highly structured cognitive-behavioural protocol. The content of the G-PST was an extended version of the problem-solving therapy approach developed by Nezu and D'Zurilla [27]: creating positive problem orientation, making a problem list, setting up priorities, identification of the most important problem, brainstorming, generating solutions, cost-benefit analysis of each chosen solution, setting up an action plan and reviewing the plan. It is important to mention that the psychological culture of the Hungarian society has traditionally been influenced by psychodynamic approaches due to historical reasons. Acquiring skills by rational cognitive-behavioural methods needs cultural adaptation and that's why a 10 -session training was applied as opposed to the original 6-session one [27].

In addition, basic cognitive-behavioural techniques were also taught such as identification of intensive emotions, cognigtive restructuring and assertive communication skills. Concerning the content of the PST special focus was placed upon the resolution of interpersonal conflicts within the family and establishing positive problem orientation because these two issues were identified as key topics as the lack of which might contribute to hopelessness in the Hungarian society. These steps were covered during sessions 1-4 while sessions 5-8 served to practice the newly acquired skills. The two booster sessions aimed to avoid relapses by creating a relapse prevention plan: each participant elaborated an individualized plan with the help of the other group members for possible future difficulties. Skill-acquisition was enhanced by behavioural techniques such as modelling, observational learning, role-play practice and feed-back. After explaining a step, the group leader demonstrated it with one of the group members who volunteered. This was followed by practice in pairs using worksheets and discussion in "large" group format. Feedback was provided at each step. Homework was also assigned after the sessions in order to practice the actual skills.

\section{Statistical Analysis}

Statistical analysis was performed by using SPSS 23. For the comparison of the effectiveness of the interventions, paired-samples t-tests were conducted. Effect sizes were calculated according to Cohen's d. Missing data were handled by multiple imputation using the Fully Conditional Specification method (FCS). In this approach, missing data are imputed by a chain of conditional distributions based on regression models using available baseline data from the responders and the non-responders. Pearson's correlation was performed to determine the relationship between problem-solving skills, depression and hopelessness.

\section{Results}

\section{Descriptive Statistics and Baseline Data}

The mean age of participants was 39.5 years; $13.3 \%$ of them were male and $86.7 \%$ female. The marital status showed a normal distribution between married (36.7\%), divorced/widowed (23.3\%) and single (40\%). 43\% of the participants were employed, $20.3 \%$ was unemployed, $11.4 \%$ seasonal employed, $8.8 \%$ was on maternity leave and $16.5 \%$ was retired/disabled. Most of them (90\%) were diagnosed with major depression while the rate of comorbid personality disorders was 10\% (Table 1). Drop out: $83 \%$ of the participants (74 persons) completed the G-PST, only 17\% (16 persons) left the program. This level of dropout rate was consistent with the literatures' findings [43]. Missing data was handled by multiple imputation using the Fully Conditional Specification method (FCS). In this approach, missing data are imputed by a chain of conditional distributions based on regression models using available baseline data. To assess for sampling bias, a comparative analysis was conducted between participants who completed the final measures and those whose data were missing at the posttreatment measurement. Results revealed no significant betweengroup differences on any baseline measure (e.g., demographics, diagnostic variables, depression, hopelessness and problemsolving abilities). 
Table 1: Demographic characteristics $(\mathrm{N}=90)$.

\begin{tabular}{|c|c|c|}
\hline & & $\begin{array}{l}\text { PST Patient } \\
\qquad \mathrm{N}=90\end{array}$ \\
\hline Age & Average (SD) & $39.5(13.2)$ \\
\hline \multirow{2}{*}{ Gender } & Male & $12(13.3 \%)$ \\
\hline & Female & $78(86.7 \%)$ \\
\hline \multirow{3}{*}{ Marital status } & Married & $33(36.7 \%)$ \\
\hline & Divorced/widow & $21(23.3 \%)$ \\
\hline & Single & $36(40 \%)$ \\
\hline \multirow{3}{*}{ Education } & University grad. & $27(30 \%)$ \\
\hline & High school grad. & $51(56.7 \%)$ \\
\hline & Elementary grad. & $12(13.3 \%)$ \\
\hline \multirow{5}{*}{ Occupation } & Employed & $39(43.0 \%)$ \\
\hline & Seasonal employment & $10(11.4 \%)$ \\
\hline & Unemployed & $18(20.3 \%)$ \\
\hline & Retired/disabled. & $15(16.5 \%)$ \\
\hline & Other (maternity leave) & $8(8.8 \%)$ \\
\hline \multirow{2}{*}{ Diagnosis } & Affective disorder & $81(90 \%)$ \\
\hline & Personality disorder & $9(10 \%)$ \\
\hline Duration of hospitalization & Months & $9.8(9.6)$ \\
\hline Number of suicidal attempts & Mean (SD) & $1.3(1 ., 4)$ \\
\hline
\end{tabular}

The Effects of PST on Problem-Solving Abilities and

\section{Coping Skills}

Table 2 shows the results of the paired samples t-test which was performed to evaluate the effect of the interventions in improving problem-solving skills based on MEPS. As expected, the number of relevant steps increased indicating very significant improvement in problem-solving skills following the training $(\mathrm{t}(89)=-3.28, \mathrm{p}<.001$, Cohen's $d=.9$ ). To investigate the effectiveness of G-PST on ways of coping (based on WAYS) we also performed paired samples t-test and a significant increase was found on the subscales of WAYS (see (Table 2): emotion-focused coping $(\mathrm{t}(89)=3.20, \mathrm{p}<.01$, Cohen's $\mathrm{d}=.5)$, planful problem-solving $(\mathrm{t}(89)=-3.09, \mathrm{p}<0.01$, Cohen's $\mathrm{d}=0.4$, small effect size), problem analysing $(\mathrm{t}(89)=--2.71, \mathrm{p}<.01$, Cohen's $d=0.4$, small effect size), emotion balancing $(t(89)=3.15$, $\mathrm{p}<.01$, Cohen's $d=.4)$ and seeking social support $(\mathrm{t}(89)=-3.15$, $\mathrm{p}<.01$, Cohen's $d=0.4$, small effect size). Our first hypothesis was confirmed since both problem-solving and coping skills showed significant increase after the G-PST.

Table 2: Comparison of problem-solving measures at pre- and post-treatment.

\begin{tabular}{|c|c|c|c|c|}
\hline Measure & M & SD & t (df) & $\begin{array}{c}\text { Sig Cohen's } \\
\text { d. }\end{array}$ \\
\hline MEPS Pre-treatment & 13.78 & 6.05 & -3.28 & $<.001^{* *}$ “ \\
\cline { 1 - 3 } MEPS Post-treatment & 15.41 & 6.91 & $(89)$ & 0.9 \\
\hline \multicolumn{6}{|c|}{ WAYS Planful Problem Solving } \\
\hline \multicolumn{6}{|c|}{ Pre-treatment } & 2.82 & 2.38 & -3.09 & $<.01^{*}$ \\
\hline
\end{tabular}

\begin{tabular}{|c|c|c|c|c|}
\hline Post-treatment & 4.12 & 2.68 & $(89)$ & 0.4 \\
\hline \multicolumn{5}{|c|}{ WAYS Problem Analysing } \\
\hline Pre-treatment & 4.71 & 2.07 & -2.71 & $<.01^{*}$ \\
\hline Post-treatment & 5.41 & 1.93 & $(89)$ & 0.4 \\
\hline WAYS Seeking Social Support \\
\hline Pre-treatment & 3.18 & 1.67 & -3.15 & $<.01^{*}$ \\
\hline Post-treatment & 3.82 & 1.60 & $(89)$ & 0.4 \\
\hline \multicolumn{5}{|c|}{ WAYS Emotion-Balancing } \\
\hline Pre-treatment & 3.53 & 1.51 & 3.15 & $<.01^{*}$ \\
\hline Post-treatment & 4.88 & 1.58 & $(89)$ & 0.4 \\
\hline \multicolumn{5}{|c|}{ WAYS Emotion Focused } \\
\hline Pre-treatment & 5.71 & 2.56 & \multirow{2}{*}{3.20} & $<.01^{*}$ \\
\hline Post-treatment & 4.59 & 2.35 & $(89)$ & 0.5 \\
\hline \multicolumn{7}{|c|}{ WAYS Escape-Avoidance } \\
\hline Pre-treatment & 6.18 & 1.64 & \multirow{2}{*}{-1.95} & \multirow{2}{*}{ NS } \\
\hline Post-treatment & 6.52 & 1.67 & $(89)$ \\
\hline
\end{tabular}

Note. Means-End Poblems Solving Scale (MEPS), Ways of Coping (WAYS)

NS $=$ not significant $,{ }^{* *} \mathrm{p}<0.01,{ }^{*} \mathrm{p}<0.5$

\section{The Effects of G-PST on Depression and Hopelessness}

Comparing pre-, and post-treatment data, there was a significant decrease in depression $(\mathrm{t}(89)=4.66, \mathrm{p}<.001$, Cohen's $\mathrm{d}=0.5$, medium effect size) and hopelessness also showed large decrease with a very strong significance $(t(89)=7.03, p<.001$, Cohen's $d=0.8$, large effect size, (Table 3). This hypothesis was also confirmed since both depression and hopelessness decreased significantly after the G-PST. Means and standard deviations are shown in Table 3. To examine if problem-solving abilities and coping skills are interrelated either to depression or hopelessness, Pearson's correlation analysis was performed. Table 4 shows that there was a moderate and very strong significant negative correlation between depression (BDI) and WAYS subscales as follows: problem analysis ( $\mathrm{r}=-.250, \mathrm{p}<.01)$, planful problem-solving ( $\mathrm{r}=-.303, \mathrm{p}<.001)$, seeking social support $(\mathrm{r}=-.278, \mathrm{p}<.01)$ and emotion balancing coping $(\mathrm{r}=-$ $.362, \mathrm{p}<.001)$. As for hopelessness we found significant correlations only on the WAYS planful problem-solving subscale ( $\mathrm{r}=-.251, \mathrm{p}<.01)$ and the emotion balancing subscale $(\mathrm{r}=-.381, \mathrm{p}<.001)$. As opposed to our expectations, MEPS scores showed no significant correlation neither with depression nor with hopelessness.

Table 3: Comparison of depression, hopelessness and number as well as emotional impact of life events at pre- and post-treatment in the PST groups.

\begin{tabular}{|c|c|c|c|c|}
\hline Measure & M & SD & t (df) & Sig. Cohen's d \\
\cline { 1 - 3 } BDI Pre-treatment & 24.04 & 13.75 & 4.66 & $<.001$ \\
\cline { 1 - 2 } BDI Post-treatment & 16.98 & 11.9 & $(89)$ & 0.5 \\
\hline BHS Pre-treatment & 10.45 & 6.41 & 7.03 & $<.001$ \\
\cline { 1 - 2 } BHS Post-treatment & 5.87 & 4.76 & $(89)$ & 0.8 \\
\hline \multicolumn{5}{|c|}{ Number of Life Events } \\
\hline
\end{tabular}




\begin{tabular}{|c|c|c|c|c|}
\hline PLES Pre-treatment & 6.63 & 4.78 & -3.01 & $<.01$ \\
\cline { 1 - 3 } PLES Post-treatment & 8.5 & 6.21 & $(89)$ & 0.3 \\
\hline \multicolumn{6}{|c|}{ Impact of Life Events } \\
\hline PLES Pre-treatment & 43.97 & 25.32 & 6.08 & $<.01$ \\
\cline { 1 - 2 } PLES Post-treatment & 34.78 & 25.91 & $(89)$ & 0.6 \\
\hline
\end{tabular}

Note. Beck Depression Inventory (BDI), Beck Hopelessness Scale (BHS),

Paykel's Life Event Scale (PLES); NS = not significant, ${ }^{* *} \mathrm{p}<0.01$, ${ }^{*} \mathrm{p}<0.5,+\mathrm{p}<.1$

Table 4: Correlations between coping measures (WAYS, MEPS) with depression and hopelessness.

\begin{tabular}{|c|c|c|}
\hline Measure & $\begin{array}{c}\text { Depression (BDI) } \\
\text { Pearson's r (Sign.) }\end{array}$ & $\begin{array}{c}\text { Hopelessness (BHS) } \\
\text { Pearson's r (Sign.) }\end{array}$ \\
\hline $\begin{array}{c}\text { WAYS - Problem } \\
\text { analysing }\end{array}$ & $-.250^{* *}(.006)$ & $-.172(.062)$ \\
\hline $\begin{array}{c}\text { WAYS - Planful problem } \\
\text { solving }\end{array}$ & $-.303^{* *}(.001)$ & $-.251^{* *}(.006)$ \\
\hline $\begin{array}{c}\text { WAYS - Seeking social } \\
\text { support }\end{array}$ & $-.278^{* *}(.004)$ & $-.186(.057)$ \\
\hline $\begin{array}{c}\text { WAYS - Emotion } \\
\text { balancing }\end{array}$ & $-.362^{* *}(.001)$ & $-.381^{* *}(.000)$ \\
\hline WAYS - Escape-avoidance & $-.071(.438)$ & $-.027(.774)$ \\
\hline $\begin{array}{c}\text { WAYS - Emotion focused } \\
\text { coping }\end{array}$ & $.058(.526)$ & $.023(.802)$ \\
\hline WAYS - Distancing & $.017(.853)$ & $-.072(.436)$ \\
\hline MEPS & $.110(.239)$ & $.094(.316)$ \\
\hline
\end{tabular}

Note. Pearson's r $(* *$ p $<0.01)$

Note. Beck Depression Inventory (BDI), Beck Hopelessness Scale (BHS),

Paykel's Life Event Scale (PLES); NS = not significant, ${ }^{* *} \mathrm{p}<0.01$, ${ }^{*} \mathrm{p}<0.5,+\mathrm{p}<.1$

\section{Life Events}

A paired-samples t-test was performed to compare the number of stressful life events and their emotional impact before and after the intervention. Surprisingly, patients evaluated the impact of their life events significantly less serious after the treatment than before according to the Paykel Life Event Scale ( $t(89)=6.08$, $\mathrm{p}<.01$, Cohen's $\mathrm{d}=0.6$ ). Unexpectedly, the number of stressful life events increased significantly at post-treatment compared to pre-treatment numbers ( $\mathrm{t}(89)=-3.01, \mathrm{p}<.01$, Cohen's $\mathrm{d}=0.3$ ). For detailed results, see Table 3 .

\section{Discussion}

In countries with moderate to high suicide rates the increased availability and easy accessibility of effective, evidence based psychological prevention methods is of utmost importance. Suicide prevention is a priority for health services all over the world especially in countries with high suicide rate. Since Hungary can be characterized by relatively high suicide rates $(24.3 / 100,000$ in 2011 and 17/100,000 in 2017), [44] several efforts have been made to reduce it. Rihmer et al. [5] in their review conclude that suicide rates can most effectively be reduced by the identification of major depression and bipolar disorder and by the better care of depressed patients. However, in addition to medication, psychosocial interventions can also be effective ways of suicide prevention. In the last decades, psychosocial interventions and learning adaptive skills to cope with low mood or stressful life events are more preferred by the patients than antidepressant medication alone [48]. Beck's cognitive model of depression and hopelessness had strongly been supported by numerous scientific research where hopelessness considered a significant predictor of suicidality. By measuring hopelessness, it is possible to identify patients at risk of suicide and deliver specific interventions on factors associated with hopelessness such as poor problem-solving skills $[14,45]$ which are in close connection with each other. Problem-solving therapy as a brief cognitive-behavioural intervention has a sound theoretical basis; however, research papers reported mixed results about its effectiveness in suicide prevention $[22,24,41]$.

In this study we presented the implementation of a culturally adapted manual based problem-solving training in our country. We developed a group format (G-PST) instead of individual format to improve access to treatment for more patients and to facilitate skill acquisition via interpersonal learning factors such as modelling, observational learning, role play and feed-back. The length of the G-PST was extended to ten sessions delivered in 12 weeks in order to consolidate the newly acquired skills. Concerning the content, special emphasis had been placed upon interpersonal problemsolving skills because this topic was identified by the patients as major origin of their distress and hopelessness. Cognitive restructuring of distorted negative thinking and the development of assertive communication skills also played an important part in the problem-solving training. Based on our findings G-PST can elicit positive changes in the low mood and hopelessness of depressed patients after a suicide attempt. As expected, G-PST resulted in a very significant improvement in problem-solving skills according to the MEPS: avoidance behaviour decreased significantly, social problemsolving skills showed significant improvement. Patients generated more relevant steps and more solutions in the interpersonal problem situations after G-PST than before (see Cohen's d=.9 large effect size for MEPS). Maladaptive problem-solving strategies (seen in the MEPS stories) such as negative problem orientation, avoidance and impulsive coping style decreased significantly (Table 2). This finding is in accordance with the model of coping described by Connor-Smith, Compas, Wadsworth, Thomsen and Saltzman [46]. It is well-validated that disengagement coping (avoidance, denial, wishful thinking) can be linked to internalizing problems. Our results corroborate that PST enhances the development of primary control coping (problem-solving, emotional expression, emotional modulation) and secondary control coping (acceptance, cognitive restructuring, positive thinking, distraction).

Coping skills also showed significant improvement on all subscales of the WAYS but the escape/avoidance subscale (Table 2). It would be interesting to know why the escape/avoidance 
subscale did not change. One explanation might be that the ability to develop assertive responses instead of escape/avoidance might require longer time than 12 weeks. However, when individuals have the ability to cope with a stressful interpersonal problem situation by cognitive skills (planning, analysing, reaching a solution) it might contribute to a more balanced emotional state (see emotion balancing in (Table 2) and to a more effective communication in order to seek help as well as social support. The significant changes of cognitive problem-solving abilities via the development of several solutions can lead to a more hopeful perspective which can contribute to a more balanced emotional state and to the decrease of hopelessness and depression (Table 3). In fact, the moderate to serious level of depression of the participants at baseline decreased significantly after the intervention and hopelessness was reduced to a large extent (large effect size). This confirms the results of other studies [47-49] that the G-PST can elicit major improvements both in low mood and hopelessness even if these factors were not directly addressed by the intervention. Also, our results show that learning new skills such as problem analysis, planful problem-solving and seeking social support as well as having emotional balance can provide protection against depression and hopelessness.

According to the cognitive theory of emotional disorders, this is not the event, but its evaluation has an emotional impact on the mood of a person. Exactly this is what was found in our study: participants evaluated the impact of their same life events significantly less serious after the intervention than before. It might mean that even if G-PST is a low-intensity cognitive intervention it still seems to be effective in restructuring distorted negative thinking and weakening the distressing effect of life events (see Table 2; $<$.01). However, the result that the number of stressful life events increased significantly at post-treatment is surprising (see Table 2; p<.01). One explanation might be that during the course of G-PST participants became more aware of their previous distressing life events or these events were somehow activated and recollected. The main limitation of our study is that no control group was used for comparison therefore the results can't solely be interpreted as an evidence of effectiveness of the G-PST. Spontaneous recovery and placebo effects might have played part in the changes also. Another limitation, that no long-term follow-up was performed after the intervention. Post-treatment assessment was carried out at the end of G-PST; therefore the scores could be proper indicators of the actual mood and hopelessness but did not allow prediction about the decrease of future suicide attempts. Follow-up assessments after a longer period would have provided a more accurate picture about the long-term effects of the interventions.

To sum up, despite of the limitations described above, the results of the study support the view that applying G-PST after suicide attempts can lead to significant positive changes in the modifiable risk factors such as depression, hopelessness and great improvement in problem-solving skills, therefore it seems to be a promising way of preventing further suicide attempts. The 10-session G-PST delivered in 12 weeks was highly supported by the participants who expressed their needs to have even more sessions in order to consolidate more deeply their newly acquired skills. Finally, we can conclude that G-PST can be used as an effective, cost-effective low-intensity, evidence based psychosocial intervention for depressed outpatients with attempted suicide in their psychiatric history. The implementation of a culturally adapted manual based problem-solving training in group format improves access to psychological treatments, allows to reach wider populations at risk. Furthermore, G-PST allows to widen the availability of PST as a low intensity intervention for mild to moderate mental health problems in schools or in general practice.

\section{Acknowledgements}

Not applicable.

\section{References}

1. World Health Organization. WHO database - Suicide rates by country (2016, 2015, 2010, 2000). Downloaded: 2021.02.17.

2. Williams JMG Van der Does AJW, Barnhofer T, Crane C, Segal Zs, et al. (2008) Cognitive Reactivity, Suicidal Ideation and Future Fluency: Preliminary Investigation of a Differential Activation Theory of Hopelessness/Suicidality. Cognitive Therapy and Research 32(1): 83104.

3. Angst F, Stassen HH, Clayton PJ, Angst J (2002) Mortality of patients with mood disorders: follow-up over 34-38 years. Journal of Affective Disorders 68(2-3): 167-181.

4. Bertolote JM, Fleischmann A (2002) Suicide and psychiatric diagnosis: a worldwide perspective. World Psychiatry 1(3): 181-185.

5. Rihmer Z, Gonda X, Kapitany B, Dome P (2013) Suicide in Hungary -epidemiological and clinical perspectives. Annals of General Psychiatry 12: 21.

6. Rihmer Z (2007) Suicide risk in mood disorders. Current Opinion in Psychiatry 20(1): 17-22.

7. Beck AT, Brown G, Berchick RJ, Stewart BL, Steer RA, et al. (1990) Relationship between hopelessness and ultimate suicide: a replication with psychiatric outpatients. American Journal of Psychiatry 147(2): 190-195.

8. Rihmer Z, Gonda X, Torzsa P, Kalabay L, Akiskal HS, et al. (2013) Affective temperament, history of suicide attempt and family history of suicide in general practice patients. Journal of Affective Disorders 149(1-3): 350354.

9. Szabó M, Mészáros V, Sallay J, Ajtay G, Boross V, et al. (2016) The Beck Hopelessness Scale: Specific factors of method effects? European Journal of Psychological Assessment 32(2): 111-118.

10. Beck A, Rush J, Shaw B, Emery G (1979) Cognitive therapy of depression. New York: Guilford Press.

11. Walker KL, Chang EC, Hirsch JK (2017) Neuroticism and Suicidal Behavior: Conditional Indirect Effects of Social Problem-solving and Hopelessness. International Journal of Mental Health and Addict 15(1): 80-89.

12. McMahon EM, Corcoran P, McAuliffe C, Keeley H, Perry IJ, et al. (2013) Mediating effects of coping style on associations between mental health factors and self-harm among adolescents. Crisis 34(4): 242-250.

13. Milnes D, Owens D, Blenkiron P (2002) Problems reported by selfharm patients: perception, hopelessness, and suicidal intent. Journal of Psychosomatic Research 53(3): 819-822.

14. Pollock LR, Williams JM (2004) Problem-solving in suicide attempters. Psychol Medicine 34(1): 163-167. 
15. Collinson M, Owens D, Blenkiron P, Burton K, Graham L, et al. (2014) MIDSHIPS: multicentre intervention designed for self-harm using interpersonal problem-solving: protocol for a randomised controlled feasibility study. Trials 15: 163

16. Poós J, Annus R, Perczel-Forintos D (2008) The investigation of problemsolving abilities of psychiatric inpatients. Psychiatria Hungarica 23(1): 42-55.

17. Ganz D, Braquehais MD, Sher L (2010) Secondary prevention of suicide. PLoS Medicine 7(6): e1000271.

18. Hawton K, Witt KG, Salisbury TL, Arensman E, Gunnell D, et al. (2016) Psychosocial interventions for self-harm in adults. Cochrane Database Systematic Review 5: Cd012189.

19. Mann JJ, Apter A, Bertolote J, Beautrais A, Currier D, et al. (2005) Suicide prevention strategies: a systematic review. Journal of theAmerican Medical Association 294(16): 2064-2074.

20. Rihmer Z, Nemeth A, Kurimay T, Perczel-Forintos D, Purebl G. et al. (2017) Recognition, treatment and prevention of suicide in adulthoode Guideline. Neuropsychopharmacologia Hungarica19: 45-51.

21. Brown GK, Jager-Hyman S (2014) Evidence-based psychotherapies for suicide prevention: future directions. American Journal of Preventative Medicine 47(2): 186-194.

22. Townsend E, Hawton K, Altman DG, Arensman E, Gunnell D, Hazell P, et al. (2001) The efficacy of problem-solving treatments after deliberate self-harm: meta-analysis of randomized controlled trials with respect to depression, hopelessness and improvement in problems. Psychological Medicine 31(6): 979-988.

23. Salkovskis PM, Atha C, Storer D (1990) Cognitive-behavioural problemsolving in the treatment of patients who repeatedly attempt suicide. A controlled trial. British Journal of Psychiatry 157(6): 871-876.

24. McAuliffe C, McLeavey BC, Fitzgerald T, Corcoran P, Carroll B, et al. (2014) Group problem-solving skills training for self-harm: randomised controlled trial. Journal of Psychiatry 204: 383-390.

25. Kendall T, Taylor C, Bhatti H, Chan M, Kapur N, et al. (2011) Longer term management of self-harm: summary of NICE guidance. British Medical Journal 343: d7073.

26. D'Zurilla TJ, Goldfried (1971) Problem-solving and behavior modification. Journal of Abnormal Psychology 78(1): 107-126.

27. Nezu AM, D’Zurilla TJ (1989) Social problem-solving and negative affective conditions. In Kendall P. C., Watson, D. (editors), Anxiety and depression: Distinctive and overlapping features 285-315.

28. Bell AC, D’Zurilla TJ (2009) Problem-solving therapy for depression: A meta-analysis. Clinical Psychology Review 29(4): 348-353.

29. Malouff JM, Thorsteinsson EB, Schutte NS (2007) The efficacy of problem-solving therapy in reducing mental and physical health problems: A meta-analysis. Clinical Psychology Review 27(1): 46-57.

30. Hatcher S, Sharon C, Parag V, Collins N (2011) Problem-solving therapy for people who present to hospital with self-harm: Zelen randomised controlled trial. British Journal of Psychiatry 199(4): 310-316.

31. The NICE Guideline on Longer-term Management in adults, children and young people (CG133) (2012). London: NICE.

32. Bennett-Levy J, Richards AD, Farrand P, Christensen H, Griffith, KM (2010) Low intensity CBT interventions: a revolution in mental health care. Oxford guide to low intensity CBT interventions. New York: Oxford University Press 3-18.

33. Cuijpers P, van Straten A, Warmerdam L (2007) Problem-solving therapies for depression: a meta-analysis. European Psychiatry 22(1): 9-15.

34. Beck AT, Ward CH, Mendelson M, Mock J, Erbaugh J, et al. (1961) An inventory for measuring depression. Archives of General Psychiatry 4: 561-571.

35. Perczel-Forintos D, Ajtay Gy, Barna Cs, Kiss Zs, Komlósi S, et al. (2012) Questionnaires in clinical psychology. Budapest: Semmelweis Kiadó.

36. Beck AT, Weissman A, Lester D, Trexler L (1974) The measurement of pessimism: the hopelessness scale. Journal of Consulting and Clinical Psychology 42(6): 861-865.

37. Perczel-Forintos D, Sallai J, Rózsa S (2010) Adaptation of Beck Hopelessness Scale in Hungary. Psychological Topics 19: 307-321.

38. Folkman S, Lazarus RS (1980) An analysis of coping in a middle-aged community sample. Journal of Health and Social Behavior 21: 219-239.

39. Rózsa S, Purebl Gy, Susánszky É, Kő N, Szádóczky E, et al. (2008) Dimensions of coping: the Hungarian adaptation of the conflict resolution questionnaire. Mentálhigiéné és Pszichoszomatika 9(3): $217-$ 241.

40. Platt JJ, Spivack G (1975) Unidimensionality of the Means-Ends ProblemSolving (MEPS) procedure. Journal of Clinical Psychology 31(1): 15-16.

41. Schotte DE, Clum GA (1987) Problem-solving skills in suicidal psychiatric patients. Journal of Consulting and Clinical Psychology 55(1): 49-54.

42. Paykel ES, Prusoff BA, Uhlenhuth EH (1971) Scaling of life events. Archives of General Psychiatry 25(4): 340-347.

43. Warmerdam L, van Straten A, Jongsma J, Twisk J, Cuijpers P, et al. (2010) Online cognitive behavioral therapy and problem-solving therapy for depressive symptoms: Exploring mechanisms of change. Journal of Behavior Therapy and Experimental Psychiatry 41(1): 64-70.

44. Central Statistical Office (2013) Accessed: 12 May 2016.

45. Cannon B, Mulroy R, Otto MW, Rosenbaum JF, Fava M, et al. (1999) Dysfunctional attitudes and poor problem-solving skills predict hopelessness in major depression. Journal of Affective Disorders 55(1): 45-49.

46. Connor-Smith JK, Compas BE, Wadsworth ME, Thomsen AH, Saltzman $\mathrm{H}$ et al. (2000) Responses to stress in adolescence: measurement of coping and involuntary stress responses. Journal of Consulting and Clinical Psychology 68(6): 976-992.

47. Huband N, McMurran M, Evans C, Duggan C (2007) Social problemsolving plus psychoeducation for adults with personality disorder: pragmatic randomised controlled trial. British Journal of Psychiatry 190: 307-313.

48. Karasouli E, Adams A (2014) Assessing the Evidence for e-Resources for Mental Health Self-Management: A Systematic Literature Review. Journal of Medical Internet Research in Mental Health 1(1): e3.

49. (2013) Diagnostic and Statistical Manual of Mental Disorders, Fifth edition. (DSM-5) American Psychiatric Association, 2013. American Psychiatric Publishing, Washington, DC, USA. 


\section{ISSN: 2574-1241}

DOI: $10.26717 /$ BJSTR.2021.34.005521

Dóra Perczel - Forintos. Biomed J Sci \& Tech Res

(C) (P) This work is licensed under Creative BY Commons Attribution 4.0 License

Submission Link: https://biomedres.us/submit-manuscript.php

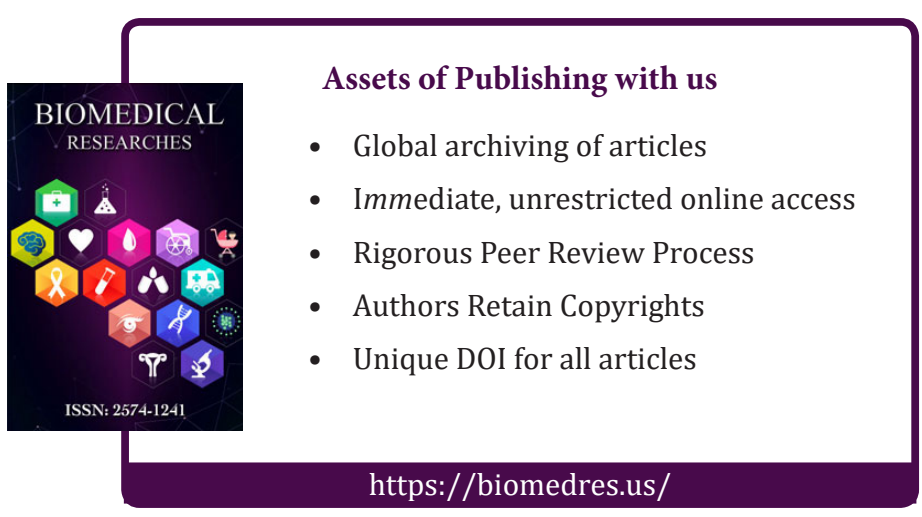

